\title{
Biografias de jesuitas realizadas por jesuitas. La edición de Guillermo Furlong sobre Ladislao Orosz y su "Nicolás del Techo"
}

\author{
Biographies of Jesuits made by Jesuits. The edition of William \\ Furlong of "Ladislao Orosz and his "Nicolas del Techo"
}

\section{Josefina Guadalupe Cargnel ${ }^{1}$}

\section{RESUMEN}

Ladislao Orosz completó en 1759 las Décadas de varones ilustres, que había comenzado a escribir Nicolás del Techo en el siglo XVII, con biografías de jesuitas que trabajaron en provincia paraguaya de la Compañía de Jesús. Las Décadas de Techo reúnen entre ocho y diez biografías por década de misioneros distinguidos durante el siglo XVII. Orosz retomó este trabajo en el siglo siguiente y amplió con cuatro nuevas décadas de biografías comenzando con la del mismo Nicolás del Techo. En esta oportunidad, nos proponemos observar el tratamiento de la biografía de un jesuita, Nicolás del Techo, por otro jesuita Nicolás Orosz a mediados del siglo XVIII, que a su vez fue recuperada por Furlong y editada durante el siglo XX. Nuestro propósito es analizar la construcción de una biografía realizada por un jesuita elegido para reseñar las vivencias de los misioneros del siglo XVIII, quien pese a ser contemporáneo de los historiadores designados por la provincia, se dedica a completar las biografías comenzadas por Techo. Asimismo nos planteamos este estudio encuadrándonos en el campo de una historia social de la historiografía, que propone abrir el enfoque historiográfico a un universo de cuestiones más amplio que los que brindaban la tradición historicista idealista y en tiempos recientes los enfoques desde la historia cultural y el narrativismo.

Palavras-chave: Biografía. Jesuitas. Historiografía. Historia colonial americana.

1 Profesora de Historia egresada de la Facultad de Humanidades de la UNNE y doctoranda en Historia en la Facultad de Filosofía y Humanidades de la UNC con el Proyecto Doctoral titulado La historiografía oficial de la Compañía de Jesús. Pedro Lozano su historiador dirigida por Dr. Martín M. Morales y co-dirigida por Dra. María Silvia Leoni encontrándome en etapa de escritura de tesis. Parte de mi investigación doctoral fue presentada en distintas reuniones científicas de mi país y de países limítrofes; así como en revistas de investigación de la especialidad. Asimismo forma parte de Proyectos de Investigación acreditados en mi Universidad y poseo categoría $\mathrm{V}$ de investigación de acuerdo al Plan de Categorización de la SPU. Me desempeño como Auxiliar docente en la cátedra "Introducción a la Historia" del Profesorado en Historia y como Adjunta a cargo de cátedra en la materia "Historia de las Instituciones" de la carrera Ciencias de la Información, ambas de la Facultad de Humanidades mencionada. Asimismo soy Becaria de Investigación Doctoral Tipo II co-financiada UNNE - CONICET. 
Ladislao Orosz completed in 1759 the Decades of illustrious males, wichthat Nicolás del Techo had begun to write in the 17th century, with biographies of Jesuit of the Jesuit province of Paraguay. Techo's Decades meet between eight an ten biographies of distinguished missionaries during the 17th century. Orosz resumed this work in the following century and expanded extended with four new biographies decades starting with the same Nicolás del Techo. In this opportunity, we intend to observe the treatment of the biography of a jesuit, Nicolás del Techo, by another jesuit Nicolás Orosz in the middle of the 18th century, which in turn was recovered by Furlong and was edited during the 20th century. Our purpose is to analyze the construction of a biography by a Jesuit priest elected to outline the experiences of the missionaries of the 18th century, who despite being contemporary historians appointed by the province, is dedicated to complete the biographies begun by Techo. Likewise weput forward this study fitting us in the field of a social history of the historiography, which proposes opening the historiographical approach to a universe of broader issues than those provided by the idealistic historicist tradition and in recent times the approaches from the cultural history and the narrative.

Keyword: Jesuits. Biography. Historiography. American colonial history.

La escritura de la provincia jesuítica del Paraguay durante el siglo XVIII es el marco que nos permite analizar las construcciones que realizaron diferentes misioneros de la región rioplantense $^{2}$ sobre la misma, plasmando sus observaciones en escritos, biografías, descripciones del espacio, de los habitantes y del entorno vegetal que los rodeaba. Al mismo tiempo, este trabajo se enmarca en el PI 007/10 Producción y circulación de saberes en la construcción de la región (siglos XVIII - XX), asentado en la Facultad de Humanidades UNNE para estudiar los esfuerzos realizados por distintos sectores para dotar a la región nordeste ${ }^{3}$ de un pasado común. Si bien nuestro interés personal se concentra en la figura del historiador de la Compañía Pedro Lozano, en esta ocasión dirigimos nuestra mirada a la escritura de otros jesuitas para observar la misma mediada por otros escritores de la Orden y poder establecer a futuro algunas líneas comunes de la producción escrita de dicha institución durante el siglo XVIII. Los objetivos de este trabajo consisten en observar la escritura de biografías a través de la obra de Guillermo Furlong "Ladislao Orosz y su "Nicolás del Techo"', planteando el estudio de dos biografías contenidas en esa obra, una escrita por Orosz sobre Techo y otra escrita por Furlong sobre Orosz.

2 Como región rioplatense entendemos los territorios que formaban parte de la Provincia Paraquaria de la Compañía de Jesús durante los siglos XVII y XVIII. Esta integraba las provincias del Río de la Plata, de Paraguay y de Córdoba del Tucumán.

3 Diferentes estudios históricos han utilizado el término "región nordeste" como sinónimo de entidades administrativas o de espacios geográficos; pese a que éstas son también productos histórico-culturales. La región nordeste, incluída en la antigua provincia paraguaya de la Compañía de Jesús, ha recibido el nombre de región chaqueña, región litoral, región mesopotámica y más recientemente, región nordeste, todas ellas denominaciones que escapan a los límites provinciales e inclusive nacionales. 
Para intentar responder estas cuestiones utilizaremos técnicas de la historia social de la historiografía que nos permitan acercarnos a la escritura, pero también al productor de la misma, para poder percibir los condicionantes de las prácticas. No pretendemos realizar aquí una biografía de los personajes presentados pero esperamos poder acercarnos al uso de la biografía y la necesidad de producirlas en distintos siglos con fines propagandísticos para la Compañía, estableciendo las similitudes que pueden señalarse entre ambas.

En este acercamiento es bueno aclarar que no abordaremos los trabajos biográficos de Orosz propiamente dichos sino extractos de ellos a partir de la edición de Furlong, ya que las Décadas publicadas en 1759 reúnen 90 biografías de las cuales Techo escribe 50 y Orosz el resto; de éstas Furlong solamente publica una - en su Colección de escritores rioplatenses, sin ofrecernos las razones de este recorte - junto a la biografía que él mismo realiza sobre Orosz. Aún así, consideramos que el trabajo permite diferentes análisis; en primer lugar el de las Décadas escritas por Nicolás del Techo durante el siglo XVII; en segundo lugar, la continuación de esta tarea por Orosz en el siglo XVIII, y por último la necesidad de Furlong, en el siglo XX, de utilizar el método biográfico para remarcar las ocupaciones de algunos integrantes de la Compañía en estos territorios. Decidimos concentrar nuestro análisis en el trabajo que Orosz realizó sobre Techo, y en la biografía que Furlong escribió sobre Orosz, ya que a través de las publicaciones realizadas por Furlong tenemos acceso directo a las biografías mencionas y no así a las escritas por Techo. Por otra parte nos interesa poder prestar atención a los usos que tenía la escritura en los siglos XVIII y XX; observando especialmente las similitudes en la escritura de ambas biografías a fin de comprender la significancia que esta tenía dentro de la Compañía y que se mantuvo después de la Restauración de la misma.

Orientamos este análisis insertos en el giro historiográfico que, según lo planteado por Michel de Certeau (1993), busca analizar el trabajo del historiador desde su propia práctica, preguntándose qué hace el historiador cuando hace historia. El gran aporte de Certeau es considerar a la práctica como una operación historiográfica que conjuga un lugar como lugar social condicionante y a la vez el contexto del historiador que permite o prohíbe ciertas prácticas; las prácticas que son propias del oficio del historiador para producir su conocimiento; y por último la escritura como el proceso y el resultado del trabajo del historiador, es decir, su producción. Con esta propuesta Certeau influye fundamentalmente en el giro historiográfico retomando el giro lingüístico pero sin quedarse solo en el análisis de la escritura. Desde esta perspectiva se propone pensar la práctica desde la propia historia, idea que se acentúa desde los '70 en la transición de una reflexión externa de la Historia a una reflexión interna, donde el cambio está basado en la cultura del texto impreso.

Consideramos que entender la historia como una construcción y como una observación de observaciones (LUHMAN, 2006) es fundamental para el estudio que realizamos porque buscamos repensar una historia colonial desde la perspectiva de quien biografía y del 
biografiado en este caso, es decir aquella realidad que se re-construye y que no podemos categorizar como "la verdad". Ya que, como afirma Lumhan, todo es atravesado por el ojo del observador lo que permite múltiples observaciones y desde esta concepción, es una construcción del historiador.

En cuanto a la historiografía jesuítica, se han realizado estudios como los de Carbia (1940), Cardozo (1959), Esteve Barba (1964) o Furlong (1959) hasta la primera mitad del siglo $\mathrm{XX}$. En estas obras el tratamiento dedicado a los autores jesuitas tiene distinta profundidad, sin embargo la mayoría son obras que engloban la historiografía jesuítica dentro de obras generales de la historiografía colonial de una región o de un país. Esta temática dejó de abordarse alrededor de la década del '50 ya que los estudios viraron hacia otros intereses, hasta que hace algunos años volvieron a producirse análisis a la luz de nuevas líneas historiográficas para otras provincias jesuíticas, como los de Palomo (2004) para Portugal, Alcantara Bojorge (2009) para Nueva España; Zupanov para India y China; entre otros. Sin duda los trabajos de Maeder (1995) y Morales (2005) representan un gran aporte tanto en cuanto a la publicación de documentos, como en el análisis desde la perspectiva del giro historiográfico en el segundo caso. Asimismo todos los estudios sobre jesuitas se vieron sumamente influenciados por la Antropología. Las tesis de Doctorado en Historia y en Antropología defendidas en los últimos años como Wilde (2003), Quarleri (2003), Paz (2009), Hosne (2009), Telesca (2009) entre otras, señalan una nueva orientación en el tratamiento de temáticas vinculadas con el mundo jesuita, desde las nuevas perspectivas historiográficas y antropológicas.

En esta oportunidad utilizaremos la propuesta de Giovani Levi sobre los usos de la biografía, donde rechaza el abordaje de las mismas como una interpretación unívoca de los destinos individuales, sino que plantea nuevas formas de abordar a los sujetos sociales (LEVI, 1989). En este sentido entendemos los diferentes análisis que se proponen, ya que sin duda los usos de la biografía son diferentes y han cambiado a lo largo de los siglos XVII, XVIII o XX; sin embargo, las tres biografías pueden formar un conjunto que respondía a los mismos objetivos que tenía la Compañía orientados a reforzar su posición y remarcar las virtudes de sus integrantes. Pese a estar escritas en contextos espacio-temporales muy diferentes, éstas biografías pueden analizarse como parte de una estrategia propagandística para mostrarse como un cuerpo fuerte y compacto pese a las divergencias internas y los ataques que la institución sufría.

La obra que estudiamos se encuentra dentro de la Colección de Escritores Coloniales Rioplatenses cuyos objetivos se concentran en dar a conocer las tareas desempeñadas por jesuitas que, según Furlong, constituyeron ejemplos de virtud dentro de la Compañía de Jesús. Para esto, realizó una selección de jesuitas y sobre cada uno de ellos realizó biobibliografías efectuando un recuento de los trabajos éditos e inéditos, para publicar al finalizar cada obra, algún documento inédito o de difícil localización del biografiado. Esta 
colección está formada por 24 números que en su mayoría abordan las vidas de los jesuitas más conocidos del espacio rioplatense. Entre ellas se cuentan "Antonio Ruiz de Montoya y su Carta a Commental", "Antonio Sepp y su Gobierno temporal", "Florian Paucke y sus Cartas al visitador Contucci", "Manuel Querini y sus Informes al Rey”, "José Manuel Peramas y su Diario del Destierro", "Joaquin Camaño y su Noticia del Gran Chaco", "Francisco Miranda y su Sinopsis", "Pedro Lozano y sus Observaciones a Vargas", "José Cardiel y su Carta Relación”, "Domingo Muriel y su Relación de las Misiones", "Bernardo Nusdorffer y su novena parte", "Tomás Falkner y su Acerca de la Patagonia”, "José Sanchez Labrador y su Yerba Mate", entre otras publicadas en Buenos Aires entre 1954 y $1972^{4}$.

\section{La escritura en la Compañía de Jesús}

Muchos autores coinciden en la importancia que tenía la escritura para la Compañía (CARBIA, 1940; Cardozo, 1959; Esteve Barba, 1964; Pino y Lázaro coord., 1995; Citro, 2006; Penhos, 2005; entre otros). Dentro de la Orden, la escritura se define a partir de la correspondencia; Ignacio de Loyola había encargado a todos los padres jesuitas en sus primeras cartas, que mantuvieran correspondencia frecuente informando todas las tareas que realizaban y la descripción de los lugares donde estaban, tanto donde eran bienvenidos como en las zonas en que se los cuestionaba. Con el correr del tiempo, esta correspondencia se convierte en un dispositivo memorístico y de propaganda para fijar una imagen de la Orden, que mantuvo su preocupación por la correspondencia ya que fue adquiriendo un

4 Guillermo Furlong. José Manuel Peramás y su Diario del Destierro (1768). Buenos Aires, Librería del Plata, 1952. (Escritores Coloniales Rioplatenses; No 1). José Cardiel, S. J. y su Carta-Relación (1747). Buenos Aires, Librería del Plata, 1953. (Escritores Coloniales Rioplatenses; $N^{\circ}$ 2). Pedro Juan Andreu y su Carta a Mateo Andreu, etc. (1750). Buenos Aires, Librería del Plata, 1953. (Escritores Coloniales Rioplatenses; No 3). Gaspar Juárez, S. J. y sus 'Noticias Fitológicas' (1789). Buenos Aires, Librería del Plata, 1954. (Escritores Coloniales Rioplatenses; No 4). Tomás Falkner y su 'Acerca de los patagones' (1788). Buenos Aires, Librería del Plata, 1954. (Escritores Coloniales Rioplatenses; $\mathrm{N}^{\circ}$ 5). Francisco J. Iturri y su 'Carta Crítica' (1797). Buenos Aires, Librería del Plata, 1955. (Escritores Coloniales Rioplatenses; No 6). Domingo Muriel, S. J. y su Relación de las Misiones (1766). Buenos Aires, Librería del Plata, 1955. (Escritores Coloniales Rioplatenses; $\mathbf{N}^{\circ} 7$ ). Joaquin Camaño S. J. y su 'Noticia del Gran Chaco' (1778). Buenos Aires, Librería del Plata, 1955. (Escritores Coloniales Rioplatenses; $\mathrm{N}^{\mathrm{o}}$ 8). Pedro Lozano, S. J. y sus 'Observaciones a Vargas' (1750). Buenos Aires, Librería del Plata, 1959. (Escritores Coloniales Rioplatenses; $\mathrm{N}^{\circ}$ 9). José Sánchez Labrador, S. J. y su 'Yerba mate' (1774). Buenos Aires, Librería del Plata, 1960. (Escritores Coloniales Rioplatenses; $\left.\mathrm{N}^{\circ} 10\right)$. Diego León Villafañe y su 'Batalla de Tucumán' (1812). Buenos Aires, Theoria, 1962. (Escritores Coloniales Rioplatenses; No 11). Antonio Sepp S. J. y su 'Gobierno temporal' (1732). Buenos Aires, Theoria, 1962. (Escritores Coloniales Rioplatenses; No 12). Justo Van Suerck y su carta sobre Buenos Aires (1629). Buenos Aires, Theoria, 1963. (Escritores Coloniales Rioplatenses; $\left.N^{\circ} 13\right)$. Francisco J. Miranda y su Sinopsis (1772). Buenos Aires, Theoria, 1963. (Escritores Coloniales Rioplatenses; No 14). Nicolás Mascardi, S.J. y su carta-relación (1670). Buenos Aires, Theoria, 1963. (Escritores Coloniales Rioplatenses; $\mathrm{N}^{\circ}$ 15). Juan de Montenegro y su 'Breve Noticia' (1746). Buenos Aires, Theoria, 1964. (Escritores Coloniales Rioplatenses; N $\left.{ }^{\circ} 16\right)$. Antonio Ruiz de Montoya y su Carta a Comental (1645). Buenos Aires, Theoria, 1964. (Escritores Coloniales Rioplatenses; N $\left.{ }^{\circ} 17\right)$. Juan de Escandón S.J. y su Carta a Burriel (1760). Buenos Aires, Theoria, 1965. (Escritores Coloniales Rioplatenses; $\left.N^{\circ} 18\right)$. Manuel Querini S. J. y sus 'Informes al Rey' 17471750. Buenos Aires, Theoria, 1967. (Escritores Coloniales Rioplatenses; N ${ }^{\circ}$ 20). Alonso Barzana S. J. y su Carta a Juan Sebastián (1594). Buenos Aires, Theoria, 1968. (Escritores Coloniales Rioplatenses; $\mathbf{N}^{\circ}$ 21). Bernardo Nusdorffer y su 'Novena Parte' (1760). Buenos Aires, Theoria, 1971. (Escritores Coloniales Rioplatenses; No 22). Tomás Fields S. J. y su 'Carta al Prepósito General' (1601). Buenos Aires, Casa Pardo, 1971. (Escritores Coloniales Rioplatenses; No 23). Florián Paucke S. J. y sus Cartas al Visitador Contucci (1762-1764). Buenos Aires, Casa Pardo, 1972. (Escritores Coloniales Rioplatenses; N 24) 
status de verdadera institución para mantener la unidad del cuerpo y del gobierno. Fue normalizada por Juan de Polanco ${ }^{5}$ quien remarcaba las letras mostrables para escribir sobre aquellos temas que había indicado el fundador: las residencias, cuantos padres eran, en que entendían, dónde y cómo vivían, las vecindades y los gentiles y constituyeron la base para presentar la historia de la Compañía, permitiendo reelaboraciones que señalaron que y como se escribe, buscando destacar solo lo edificante, instalando también la idea de letras no mostrables.

Asi, a través de las primeras cartas - y luego establecidas en las Reglas de la Compañía de Jesús - se reglamentaba no sólo la vida de los padres sino también qué, cómo y la forma en que se debía escribir para generar estrategias de gobierno y cohesión así como de representación del cuerpo. Esta escritura se inscribe en la noción de Martín Morales de mostrar y encubrir (MORALES, 2005, p. 45), donde remarca que todos los misioneros tenían presente un marco de lo que podía decirse, aquello que podía mostrarse porque era edificante para la Compañía y al mismo tiempo lo que debían ocultar, como las disidencias internas, los conflictos y todas aquellas cuestiones donde la Orden no sobresaliera. Según este autor, esta regulación está presente en toda la producción de la Compañía, siempre que no fueran las cartas espontáneas que podían escribirse entre los misioneros, al provincial o al general.

Esta producción escrita que la Compañía de Jesús generaba desde sus provincias tiene sus orígenes en las primeras historias que buscan reseñar la vida de su primer General Ignacio y la fundación de la Compañía. La misma institución mantuvo diferentes posturas frente a la escritura de biografías, comenzando por la de su fundador, que dictaba sus relatos a Luis de Gonzalvez de Camara, su primer biógrafo, pero sin estar presente en el texto ya que Ignacio no la escribía ni releía los escritos de Gonzalvez; este primer texto se pierde y con él la imagen de hombre simple y humilde que Ignacio pretendía dejar. Muchos años después de su muerte, Francisco de Borja, siendo general de la Orden, encarga a Pedro de Ribadeneyra que hiciera una biografía de Ignacio, para escribir del "hombre que fue entre sus días" recordando a Ignacio como un hombre simple y humilde y no como un santo lejano; diferenciándolas de las otras biografías que se escribían sobre el fundador que perseguían engrandecerlo, inaugurando así una costumbre de remarcar los hechos sobresalientes de las vidas dignas de imitar (MORALES, 2005). Ese intento de Pedro de Ribadeneyra de abrir un camino que llevara al origen a través de la biografía del fundador, se continuó con los escritos de Juan de Polanco, quien a través de su Cronicon intentó rescatar las historias de los fundadores. Ambos marcan algunas líneas, como la cercanía temporal como expresión de veracidad; ya que consideraban que cuanto más se alejaban del

5 Juan de Polanco (1517-1576) fue de los primeros compañeros de Ignacio en la fundación de la Orden. Fue secretario de los tres primeros Generales y tuvo una labor muy importante dentro de la Orden como secretario, teólogo y organizador durante el generalato de Ignacio. Muchos lo señalan como el poder en la sombra ya que dedicado Ignacio a lo espiritual él se revestía de la figura del General para lo administrativo teniendo un papel fundamental en la estructura interna inicial de la Compañía. 
momento se podían confundir los hechos, así como la idea de que lo que no se escribe desaparece porque la memoria se olvida y con ella la historia. Estas primeras biografías dan origen a la necesidad de los jesuitas de escribir historias de vida sobre compañeros.

A partir del siglo XVII la Compañía puso en práctica un proyecto historiográfico que señalaba la necesidad de escribir su historia y la actuación de los jesuitas en cada provincia, para esto señaló en cada provincia la designación de padres historiadores; es decir, algunos jesuitas para los cuales su tarea misional consistía en escribir la historia de la Compañía. Sin embargo la escritura, para la Compañía de Jesús, no era privativa de quien tuviera el cargo de historiador, sino que les pertenecía a todos los integrantes - en tanto que muchos de ellos consiguieron publicar sus obras poco después de escribirlas - ya que la Compañía se representaba y se establecía dentro de un sistema retórico que era conocido por todos los jesuitas y su desarrollo como orden religiosa coincide con un momento de cambio y de transformaciones sociales, dentro de las cuales la imprenta generó el paso de una cultura mayormente oral a otra que poco a poco va a asentarse en los textos escritos. Así la Compañía, con una formación que se basa en los ejercicios espirituales jalonada por textos impresos, se asienta sobre dicha cultura escrita, en la cual los libros ocuparán un papel primordial. Por esto debemos tener en cuenta el concepto de autor que existía en el siglo XVIII, así como el de biografiado, que nos lleva a pensar la idea del individuo desde los parámetros del siglo XVIII.

A través de la escritura, la jerarquía impuesta por la Orden se aseguraba el principio de omnipresencia (JAOLINO TORRES, 2008, p. 4), ya que todos los padres tenían obligación de enviar la correspondencia - sus cartas personales, oficiales y los informes de cada provincia - respetando las jerarquías establecidas. Esta escritura dentro de la Compañía formó un tejido que intentaba mantener unido el cuerpo y al mismo tiempo condicionaba la configuración de las prácticas que se realizaban en torno a la escritura. Es posible pensar que ese control disciplinar era vulnerado a través de distintas resistencias y de allí la importancia otorgada a la escritura frente a la vulnerabilidad que dicho control había mostrado; al mismo tiempo que era reforzado constantemente en las cartas de los superiores. Se ha hablado mucho de la escritura propagandística de la Compañía, consideramos que esta producía una "ilusión de realidad" (BARTHES, 1997), ya que la institución fue tratando, en distintas épocas mediante diversas formas discursivas, de construir un discurso identitario y en este sentido era de propaganda o apologética.

Federico Palomo (PALOMO, 2004), analizando la relación de misiones rurales de Portugal, afirma que el impulso por escribir estaba signado por la obligación, que conllevaba al mismo tiempo la necesidad de fijar la palabra, ya que la palabra emitida en el púlpito era volátil porque no se asentaba para la relectura, como si podía hacerse con la palabra escrita. Esta misma necesidad de fijar las palabras se observa en las biografías ya que Orosz (1966, p. 103) afirma de Techo que: 
Siempre valiente, mientras se ejercitaba en la salvación de las almas los superiores le indujeron a que se valiera de la pluma para ilustrar la provincia del Paraguay y sacara del olvido de los hombres y de las tinieblas, las cosas que los jesuitas habían realizado.

Mientras que Furlong lo expresa en estas palabras al hablar de Orosz:

Por el conjunto de sus dotes físicas, morales e intelectuales y por el excelente uso que supo hacer de los dones de la naturaleza y de gracia con que estaba enriquecido fue Orosz uno de los jesuitas más egregios con que contó la provincia del Paraguay (FURLONG, 1966, p. 5).

Por otra parte la escritura era una preocupación muy importante de la Compañía, por que el registro escrito de los sucesos se entendía como la custodia del registro en sí mismo (JAOLINO TORRES, 2008); quizás por esto la necesidad de remarcar las tareas y las virtudes personales en las biografías, que pretendían formar ejemplos a seguir para los novicios así como para efectuar el control de lo que se decía:

"Pasados los años de teología en el Paraguay, dio muestras de sólida virtud y ciencia [Nicolás del Techo] de modo que... se unió más estrechamente a Dios y a la Compañía por la profesión de cuatro votos" (OROSZ, 1966, p. 101).

Asimismo remarcamos la importancia de los archivos para la Compañía, ya que el archivo jesuítico no era concebido solamente como un lugar para la guarda de los documentos, sino como un administrador y re-elaborador de la información circulante y de los registros. En este sentido se daban indicaciones concretas sobre qué se debía escribir, dada la importancia del papel como criterio de que "aquello que está escrito es la verdad" (JAOLINO TORRES, 2008, p. 10).

No se establecía claramente la lengua en la que se debía fijar dicha palabra; podemos suponer que en lenguas vernáculas y no en latín, para que estuvieran al alcance de mayor población o quizás se esperaba que se escribiera en latín por la universalidad del mismo. Sin duda el idioma en que se escriben las biografías es otro aspecto a señalar ya que no solo no se escriben en latín, sino que a su vez se traducen a otras lenguas vernáculas, lo que demuestra la pérdida de centralidad que va teniendo dicho idioma.

Es bueno remarcar con las citas presentadas que pese a que la primera es del siglo XVIII y la segunda del XX, podemos observar que en ambas se repiten las ideas sobre las dificultades que presentaba el dedicarse a la escritura. Podemos pensar que esta tarea estaba 
devaluada en ambos siglos y que se convirtió en un topos de la escritura jesuítica ${ }^{6}$; por esto la necesidad de igualarla a la de misionero, que era la tarea más destacada y el destino esperado de todos los jesuitas que llegaban a América. En este sentido, es significativo que en diferentes siglos ambos escritores coincidan en el intento de igualar las tareas a través del mismo topo remarcando a aquellos que se dedicaban a la escritura mediante caracterizaciones como "misionero insigne" o "jesuita destacado".

\section{Nicolás del Techo, Ladislao Orosz y Guillermo Furlong}

Nicolás del Techo nació en 1611 en una ciudad al norte de Francia, según Storni en su catálogo, aunque Orosz consigna su nacimiento en la ciudad de Lieja en Bélgica; ingresó a la Compañía en 1630 y llegó a Buenos Aires en 1640. En 1649 realizó el cuarto voto en Itapúa y a partir de ese momento se desempeñó como Superior de las misiones y efectuó también su tarea como historiador de la provincia. Falleció en 1685 en la misión de San Nicolás (STORNI, 1980, p. 87). Dentro de su tarea como historiador se destacó con numerosos trabajos y principalmente la primera historia conjunta de las acciones de los misioneros jesuitas en estas provincias - la Historia Provinciae Paraquariae - publicada en Lieja en 1678. De esta obra existe una sola traducción completa al español, realizada por Manuel Serrano y Sanz y publicada en Madrid en 1897, como parte de la Biblioteca Paraguaya dirigida por Blas Garay, de quien es el prólogo que encabeza dicha edición.

De acuerdo al mismo catálogo, Ladislao Orosz fue un sacerdote jesuita profeso de 4 votos, es decir que tenía el cuarto voto de obediencia al Papa, que le brindaba a la Orden alguna de sus características particulares. Ingresó a la Compañía en la provincia jesuítica de Viena y después de muchos pedidos fue destinado a la provincia del Paraguay. Siendo estudiante en Viena desde 1716 solicita en varias cartas al general Tamburini ser designado a las misiones americanas, llegó a Buenos Aires en 1729 como sacerdote y completó sus estudios en Córdoba donde también se desempeñó como profesor de Filosofía. Con el tiempo fue elegido procurador por el cuerpo de la provincia reunido en congregación provincial, después de haber sido maestro de novicios y para 1750 es uno de los consultores ${ }^{7}$ de la provincia y de los que redacta y firma la "Representación hecha por parte de la provincia jesuítica del Paraguay al virrey y a la audiencia" por las consecuencias que tendría

\footnotetext{
6 Hemos encontrado referencias en otros escritos jesuitas sobre la intención de negarse a trabajar en la escritura por no considerarse capaz para ello; expresiones como "con arduo temor y repugnancia mía" de Lozano de 1745 entre otras que nos conducen a pensar que la escritura no era una tarea deseada entre los jesuitas.

7 Maestro de novicios y consultor eran cargos importantes dentro de la estructura de la Orden. El primero tenía a su cargo la formación de quienes aspiraban a convertirse en jesuitas y el segundo era un cargo designado por el provincial, para consultas sobre diferentes índoles. El derecho de la Compañía preveía que el provincial tuviera que oír a los consultores, por lo que estos funcionaban también como control del provincial
} 
para las misiones del Uruguay, el tratado de límites firmado entre Portugal y España en 1750. Estaba en Córdoba cuando llegó la orden de expulsión y desde allí fue hacia su patria natal, Eslovaquia, donde murió en 1773. (STORNI, 1980, p. 207).

Furlong afirmaba, a través de las cartas escritas por Orosz, que este se lamentaba muchas veces por no poder estar cerca de los indios. Era común entre los jesuitas designados a tareas que no fueran el trabajo en las reducciones que se "quejaran"; la evangelización de indígenas era vista como el destino privilegiado para ser un misionero de Dios y asimismo como una vía de santificación para convertirse rápidamente en mártir. Por esto Orosz escribía varias cartas sobre las actividades que le habían sido asignadas que no eran de su agrado: "estoy en el Colegio Máximo de Córdoba y con confusión mía le participo que estoy condenado a enseñar la filosofía sin duda...para purgar mis pecados" (FURLONG, 1966, p. 18). Como decíamos es común observar estas expresiones entre los jesuitas que no eran destinados a las misiones; y quizás, al mismo tiempo, esa queja se convertía en un topos que reafirma la obediencia al remarcar el esfuerzo con el que afrontaban las tareas asignadas. Aunque, sin duda, también debemos entenderlo como un recurso retórico que pretende remarcar que nadie es suficientemente útil para las tareas que se le asignan; idea que se reforzaba en las Reglas por las cuales debían buscar al Señor a través de la mortificación y la abnegación:

El hecho puede servir de ejemplo a los jóvenes para comprender como han de deshacerse de las trabas que la carne y la sangre les ponen en negocios semejantes y con que desprecio varonil de todo respeto humano hay que alistarse bajo la bandera de Cristo (FURLONG, 1966, p. 26).

En 1744 Orosz fue elegido procurador para las cortes de Roma y Madrid junto a Bruno Morales y Simón Ballina con el objetivo de conseguir autorizaciones para aumentar el número de misioneros en los envíos y para conseguir la autorización para abrir otro colegio en Buenos Aires. En este viaje tuvo contacto con Muratori, con quien mantendría correspondencia fluida, ya que con sus noticias es uno de los que nutre la segunda parte de El cristianismo feliz. En 1749 vuelve a ser rector del colegio de Monserrat y maestro de novicios. Para esta fecha completa las Décadas de Nicolás del Techo que consiguió publicar como un solo libro en 1759. Este libro contenía biografías de jesuitas destacados agrupados por décadas; sin embargo las escritas por Orosz son - según Furlong - más abundantes en detalles históricos y geográficos y de personas que él conoció. Esto nos presenta una cuestión fundamental relacionada con la escritura, ya que para esa fecha el historiador oficial de la Orden para la provincia del Paraguay era Pedro Lozano, sin embargo muchos de los padres escribían crónicas, noticias y biografías; por lo que nos preguntamos sobre la necesidad del cargo de historiador, seguramente si todos podían escribir sobre temas 
históricos, el historiador era el encargado entonces de generar la memoria oficial de la provincia.

La tarea de Orosz en el colegio Monserrat también era remarcada, ya que como rector fue quien encargó la imprenta, la instaló en dicho colegio y consiguió el material y el personal idóneo para imprimir algunos libros; aunque llegaron a editarse muy pocos ya que se instala en 1764, pocos años antes de que los jesuitas fueran expulsados. En 1767 la expulsión lo encontró en Córdoba y de allí volvió a Eslovaquia, para desempeñar tareas en el colegio local, aunque siguió en permanente contacto a través de la correspondencia con sus compañeros rioplatenses hasta su muerte. Orosz tiene numerosos escritos que fueron publicados como las décadas, memoriales, y algunas cartas; sin embargo gran parte de sus trabajos quedaron inéditos como los tratados para el colegio, catálogos, cartas y representaciones al virrey por el Tratado de Límites de $1750{ }^{8}$

Para poder comparar la escritura de Orosz con la de Furlong, de acuerdo con el marco teórico con el que trabajamos, necesitamos señalar algunos datos biográficos de Furlong que nos permitan pensar en el lugar que ocupó en esa operación historiográfica. Nació en Argentina en 1889 y fue un destacado investigador de la historia colonial y de la Iglesia en América, ingresó a la Compañía de Jesús estando en Estados Unidos y desde allí regresó al país, donde se desempeñó como profesor de Historia y de Lengua Inglesa en el colegio del Salvador. Iniciado y orientado en su carrera de investigador por el historiador Enrique Peña, en 1939 fue designado miembro de la Academia Nacional de la Historia, en la que destacó por su amplísima producción literaria que abarca más de 80 libros e innumerables aportes en publicaciones periódicas y obras generales.

Furlong se dedicó de manera incansable a escribir sobre la actuación de los jesuitas y la Orden en la región. En ese esfuerzo por señalar sus tareas también se interesó por ubicarlos en un contexto y darle continuidad al relato de Historia Argentina, integrando un grupo de historiadores que se dedicaron a buscar los orígenes de una Argentina católica. Para Ayrolo "Furlong promueve de forma permanente en casi todas sus obras una historia católica de la Argentina presentando la nación como producto de la inspiración religiosa católica muy anterior a 1810". (AYROLO, 2000, p. 50). 


\section{Algunas observaciones sobre las biografias de jesuitas realizadas por jesuitas}

Partiendo de la idea planteada por Luhman sobre la observación de observaciones, como una manera de estudiar el pasado colonial y remarcando que entendemos la historia como una construcción del historiador, que no podemos categorizar como "la verdad" ya que es la observación que aquel realizara sobre su realidad. Queremos concentrar este trabajo sobre algunas biografías realizadas por jesuitas; para esto elegimos las Décadas de padres ilustres. Este libro publicado en 1759 está formado por dos partes, una sección con autoría de Techo, donde consignó cinco décadas con diez biografías cada una; este trabajo quedó inédito y fue continuado por Orosz un siglo después, quien agregó cuatro décadas de diez biografías cada una nuevamente y consiguió posteriormente su publicación en Europa. Nosotros trabajamos con la biografía que realizó Furlong sobre Orosz, que acompaña la publicación de la biografía que Orosz realizó sobre Nicolás del Techo y que da comienzo a su sección de las Décadas.

La obra que trabajamos es parte de una colección realizada por Furlong, como señalamos, en la que presenta biografías y un texto inédito que él elegía sacar a la luz, sin embargo desconocemos por qué eligió publicar nuevamente la selección de la biografía de Techo si ésta ya había sido publicada. Quizás una de las razones sería la dificultad de acceder a la obra, ya que la edición era muy antigua y por esto se decide a rescatarla; aunque nos preguntamos entonces por qué solo publica esa biografía y no todas las décadas que redactó Orosz o al menos una década completa. Otra razón posible de esta elección podría deberse a la confusión sobre quién era el autor de las Décadas de Varones Ilustres; confusión que él resuelve al ver el libro y observar dos portadas que señalaban una pars prima y una pars seconda, debidas a Techo la primera y a Orosz la segunda, pero publicadas como un solo libro; sin embargo estas son razones inferidas ya que Furlong no explicita las suyas en el libro'.

9 Dentro de la primera parte se encuentran:

Década 1: Alonso Barzana, Juan Saloni, Manuel Ortega, Tomás Fields, Juan Romero, Gaspar Monroy, Pedro Añasco, Luis Valdivia, Marcelo Lorenzana y Juan Dario. Década 2: Diego de Torres, Martín de Aranda, Horacio Bechio, Juan Viana, Melchor Venegas, José Cataldino, Simón Maceta, Juan Vaseo, Juan Pastor. Década 3: Roque González, Alfonso Aragona, Diego Boroa, Claudio Ruierius, Pedro Espinosa, Cristobal Mendoza, Pedro Mola, Eugenio Vallodano.

Década 4: Pedro Romero, Mateo Fernández, Diego Ranzonier, Nicolás Enarte, Gaspar Osorio, Antonio Urtasun, Diego Salazar, Diego Alfaro. Década 5: Francisco Diaz Taño, Alfonso Arias, Pedro Marques, Justo Mansilla, Domingo Munioca, Juan Suarez, Francisco Jiménez, Pedro Álvarez, José Oregio y José Domenech.

A estas décadas Orosz le agregó otras cuatro con numeración continua pero separadas en el título como pars secunda, Década 6: Nicolás del Techo, Gonzalvo Juste, Bernardino Tolo, Sebastián Discreti, Juan Salinas, Miguel Serra, Antonio Fieldi, Juan Neuman, Simón de León. Década 7: Enrique Adam, Francisco Rojas, Lucas Cavallero, Jerónimo Delfin, Bartolomé Blende, José Arce, Diego Francisco Altamirano, Bartolomé Giménez, Blas Silva, José Masso. Década 8: Antonio Parra, Lauro Núñez, Juan Cea, Alberto Romero, Francisco Hervás, Francisco Burgués, Antonio Sepp, Juan Alferez, Luis Roca, José Ignacio de la Mata. Década 9: Julián Lizardi, Ignacio Arteaga, Martín López, Paulo Restivo, Nicolás Ignacio de la Roca, Antonio Ribera, Pedro Quintela, Juan Elliot, Jerónimo Herrán y Agustín Castañares. 
La historiografía ha utilizado la biografía con distintos objetivos según el momento en el que se desarrollaba, comenzando en la Antigüedad con las Vidas paralelas de Plutarco para formar un modelo de hombre y después para resaltar la vida de los reyes y de los santos; estas hagiografías son revisadas durante la Edad Moderna especialmente por los grupos católicos para escribir vidas de santos descartando las leyendas y los documentos fraudulentos. En el siglo XIX se acentuó la historia de los grandes hombres como los hacedores de la historia de los estados; en el siglo XX con la escuela de Annales fue analizada nuevamente y desprestigiada esta corriente, exceptuando los trabajos de Febvre. En los años 80 los estudios biográficos resurgieron con nuevos objetivos que la diferencian de la biografía tradicional.

Para Giovanni Levi la nueva dimensión biográfica procura mostrar la complejidad de la identidad, por esto propone cuatro tipos de biografías para reducir la escala de observación, así como niveles y usos de la biografía, presentando Prosopografía y biografía modal, Biografía y contexto, La biografía y los casos límite, Biografía y Hermenéutica; destacando en todos la relación entre biografiado y contexto (LEVI, 1989). Así, el análisis basado en un hombre brinda la posibilidad de reconocer un tejido a partir del cual resulte posible obtener la imagen gráfica de la red de relaciones sociales en la que el individuo está integrado, como un enfoque de redes como el que proponía Zacarías Moutokías (MOUTOKÍAS, 2000). En este retorno a la biografía, Carbonari plantea que dentro de los debates historiográficos actuales lo que está en discusión no es la historia de vida de una sola persona sino lo que se pretende mostrar con esta trayectoria (CARBONARI, 2003). En este sentido es que creemos útil prestar una mirada atenta a la escritura de las biografías escritas por jesuitas en distintas épocas, ya que esto puede ayudarnos a comprender la trayectoria de la Compañía a través de la escritura.

Pese a ser biografías de siglos diferentes indudablemente podemos ubicarlas en la clasificación que ofrece la historia de la historiografía dentro del género biográfico que surgió con una orientación pragmático - política, en la cual las historias de vida eran arquetipos y sus conductas eran dignas de ser imitadas. Podemos pensar que las biografías analizadas se construían como modelos de virtud a imitar y que reflejaban las tareas de la Compañía en estas provincias. Dándole un uso un tanto anacrónico por una parte y por otra parte dejando de lado la cuestión de los mismos intereses de los jesuitas.

Furlong solo nos ofrece la primera de las biografías realizadas por Orosz, sobre la vida de Nicolás del Techo. Orosz destacaba en esta biografía la tarea de Techo y su desempeño en la escritura con estas palabras, explicando también por qué fue Techo el elegido para comenzar las nuevas décadas: 
Seáme permitido [...] hablar en primer lugar de las cosas hechas por el padre Nicolás del Techo que con el mismo nombre mereció preclaramente de esta provincia porque con su pluma muy feliz escribió la historia de la misma y por eso transmitió a los descendientes, con narración divina, los varones más ilustres de la misma provincia. (LADISLAO OROSZ, 1966, p. 101).

Pero nuestra preocupación fundamental para este trabajo es quien construye la historia, para qué y con que fuentes lo realiza. Carbonari afirma la cercanía de historia y biografía y cómo en algunas oportunidades se confundía la historia de una época con la vida de un gobernante (CARBONARI, 2003). En nuestro análisis no se observa esta confusión, ya que si bien Orosz entrelazaba la vida de Techo con el contexto, este no definía ni intervenía en el devenir de los sucesos que relata:

Toleró con ánimo tan valiente la sed, el hambre y las otras penurias de la vida que en semejantes excursiones se presentaban abundantísimas que los veteranos luchadores de Cristo se admiraban de soldado recientemente incorporado y juzgaron que en este fecundísimo campo de trabajos, más bien había que moderarlo, en vez de excitarlo (LADISLAO OROSZ, 1966, p. 101).

En la obra de Furlong, la historia está centrada en las actuaciones de Orosz para dejar "de lado" el contexto analizado en otras de sus obras, coincidiendo con la centralidad de sus objetivos. En este sentido resultan más útiles las ideas de Levi quien afirma que en la revalorización de la biografía se la vincula al contexto, afirmando que en dicho entorno son capaces de caracterizar una atmósfera que explica su singularidad (LEVI, 1986).

En este sentido nos preguntamos por los objetivos de cada uno para escribir estas biografías, principalmente nos interesa el contexto del mismo Orosz. Una primera cuestión que desconocemos es la fecha en la que Orosz escribe las Décadas, el libro se publica en 1759 muchos años después de su viaje como procurador en los años '40. Según lo que refiere Furlong, entre las tareas que Orosz desempeñó en las cortes de Madrid y Roma, no tuvo oportunidad de discutir sobre la publicación de su obra, lo que nos permite inferir que la escribió a su regreso mientras era Maestro de novicios. Sin duda desde su posición de maestro necesitaba mostrar modelos de misionero y por esto se embarca en la recuperación de la Décadas. El contexto de los años '50 - Orosz vuelve en 1749 y es designado rector del colegio Monserrat - presenta a la Compañía en graves dificultades asociadas al Tratado de Madrid, sin duda en la Córdoba de aquellos años existían tantos detractores como benefactores de la Compañía de Jesús, que remarcaban la necesidad de la institución de construir modelos a seguir. Por los escritos de Orosz sabemos que él había escuchado en Europa los comentarios alrededor del tratado que se firmaría entre España y Portugal y 
había tenido que negociar la ampliación de permisos para el envío de misioneros; esto le brindaría una mirada especial para su trabajo y un interés en rescatar las tareas de jesuitas destacados para reforzar el papel de la Compañía.

Si bien nos concentramos en Orosz, es bueno tener presente que en el caso de Techo, este escribía en el momento de asentamiento, expansión y consolidación de las misiones jesuíticas de guaraníes, y cuando éstos encontraron, pese a las conocidas dificultades en el afianzamiento, la manera de mantener fortalecidas esas reducciones. En el caso de Furlong es bueno remarcar que su escritura está condicionada no sólo por su pertenencia, sino también por la configuración del campo historiográfico que fue definiendo su "hacer", su trabajo histórico; asimismo este posee las características que proponía la Nueva Escuela Histórica ${ }^{10}$ de la cual Furlong era un activo partícipe.

Para poder enmarcar estas biografías consideramos algunos de los modos de biografía propuestos por Levi, ya que nos parecen adecuados para entender el trabajo de Orosz. El modo de prosopografía y biografía modal hace referencia a la utilización de datos biográficos para fines prosopográficos; es decir utilizar parte de los datos biográficos para poder describir el exterior de una persona. A través de este sistema Levi afirma que se pueden señalar las diferencias y desviaciones que pueden reflejar características estructurales propias y comunes al grupo estudiado así como rechazar las diferencias y desviaciones. (LEVI, 1989, 56). Para estrechar las características del personaje a las de la comunidad que este representaba, Ladislao Orosz (1966, p. 102), expresaba de Techo:

Haciendo la tercera probación, según las disposiciones de nuestro Instituto y ardiendo admirablemente por la salvación de las almas, partió con gran tenacidad, a la abundantísima mies de los Guaranies o Guairaníes. Apenas alcanzó la primera etapa, se entregó totalmente a aprender la lengua de los pueblos guaraníes.

Por otra parte tanto Orosz como Furlong se proponían realizar biografías de tipo modal, es decir aquellas que buscan establecer ejemplos de conducta que ilustren formas típicas de comportamiento, por esto son empleadas para enunciar las normas y reglas estructurales de cómo debían comportarse los jesuitas según el oficio que tuvieran que desempeñar. Así, las características configuradoras de la biografía de Orosz señalaban virtudes de Techo, resaltando sus tareas como sacerdote trabajador, misionero incansable, varón preclaro y

10 En líneas generales se denomina Nueva Escuela Histórica al movimiento historiográfico de Argentina, desde la segunda década de este siglo; surge desde las universidades y se caracteriza fundamentalmente por la aplicación rigurosa de los criterios metodológicos que se difundieron en Europa en la segunda mitad del siglo XIX, en una concepción nacional y americanista de la historia argentina. Cristina Pompert de Valenzuela. "La Nueva Escuela Histórica (1905 - 1947) su proyección en influencia en la historiografía argentina". En: Folia $\mathbf{N}^{\circ} 10$. Resistencia, Fac. de Humanidades - UNNE- IIGHI - CONCIET, 1991 
religiosísimo, historiador, entre otras. Furlong a su vez destacaba estas mismas características en Orosz con estas palabras:

\begin{abstract}
Al segundo rectorado del Padre Orosz en el Colegio--Convictorio de Monserrat corresponde uno de los hechos más conspicuos y auspiciosos en la historia cultural del pueblo cordobés y aun en el argentino: la introducción de la primera imprenta, que funcionó en la docta ciudad del interior. (FURLONG, 1966, p. 55).
\end{abstract}

El modo Biografía y contexto realza el entorno del personaje por considerarlo condicionante, creyendo que se necesita pensar en el contexto que las hace posibles (LEVI, 1989, p. 57). Orosz en la biografía de Techo subrayaba el contexto en el que Techo se santifica, como ese espacio de afianzamiento y conformación a través de los grandes sacrificios que remarcaba había realizado:

Pasados los años de teología en el Paraguay, dio muestras de sólida virtud y ciencia, de modo que, a su tiempo esto es en el año cuadragésimo nono del mismo siglo, se unió más estrechamente a Dios y a la Compañía por la profesión de cuatro votos (LADISLAO OROSZ, 1966, p. 101).

En un contexto muy diferente Furlong repite este sistema para destacar al misionero elegido permitiéndonos pensar que hay una estructura de biografías como modelo de vida que se mantenía dentro de la escritura de la Compañía en el siglo XX:

Cuando la ciencia y la experiencia anidan en una alma santa y está ésta al servicio de los prójimos, se tiene lo que es tan raro y difícil de hallar: un consejero y mentor espiritual y según todas las señas, el padre Orosz fue uno de esos hombres excepcionales. El mismo hecho de habérsele nombrado resolutor de casos de conciencia es un indicio de su especial capacidad para esa difícil labor. (FURLONG, 1966, p. 67).

La hipótesis de Levi se basa en que las historias de vida no pueden componerse a través de sus singularidades sino resaltando el lugar que ocupan en el contexto histórico que las autoriza (LEVI, 1989, p. 57). Pero el peligro de esta visión es caer en posiciones deterministas donde el contexto es un telón de fondo inmóvil que condiciona las elecciones. Indudablemente la misma Compañía era el gran telón de fondo y las misiones entre indígenas eran el escenario donde los misioneros podían destacarse; quizás por eso la 
mayoría de los jesuitas solicitaba las misiones como destino, mientras que cualquier otra ocupación que no fuera entre los infieles era menospreciada por la necesidad de mostrar el sacrificio que se convertía en un suceso exitoso a fines de la propaganda. Sin duda este escenario está construido a través de las cartas y de la historiografía oficial que emanaba de la misma institución; consideramos que la Compañía pretende mostrar un escenario que era a la vez tan fructífero como espinoso. En este sentido, si el éxito estaba representado por las misiones de guaraníes, éstos ya no podían ser considerados como infieles en el siglo XVIII, aunque quizás sigue siendo un destino deseado porque existían ciertas contemplaciones para los que estaban en misión entre indígenas; por otra parte en la ideología jesuítica el indio nunca está completamente convertido, siempre sigue siendo infiel y por esto debe ser guiado en el camino de Cristo mediante la mano del jesuita. Sin duda también debemos tener en cuenta que seguramente se colarían entre los deseos de los misioneros las propias ambiciones personales, que pese a las reglas de humildad, obediencia y la búsqueda permanente de Cristo en los oficios más bajos, es común observar los llamados de atención por cuestiones como la búsqueda de rédito personal, de destacarse o de sobresalir entre los compañeros.

En el caso analizado, el recorrido de Techo por el colegio, las misiones y por diferentes cargos dentro de la provincia paraguaya le ofrecían un medio para destacarse en las virtudes mencionadas. Un análisis simple sería pensar que otros padres en el mismo contexto no se destacaron y por eso no son dignos de que la memoria los recuerde, mientras que los elegidos para biografiar si lo son. Sin embargo en un análisis como el que proponemos, pensando en la operación historiográfica que se realiza desde el contexto de Orosz, podemos pensar que los biografiados eran funcionales a las necesidades de la Compañía, entendiendo esa funcionalidad como rentables al discurso que la Compañía pretendía brindar en cada momento histórico. Sin duda debemos tener en cuenta en esta observación las redes personales de los biografiados, pensando que quizás elegían los protagonistas entre sus amigos, especialmente cuando realizan biografías de contemporáneos. Una lectura ingenua de la producción de la Compañía puede llevarnos a pensar que elegían objetivamente a aquellos padres "dignos de recuerdo"; pero desde ese lugar corremos el riesgo de caer en análisis apologéticos que nos impidan pensar en otro tipo de estudio, limitando nuestra mirada a los lugares comunes que presentaban los mismos jesuitas a través de las biografías. Por esto intentamos tener presente que, tanto las biografías como los análisis que realizamos, son construcciones de hechos que sucedieron o de las tareas realizadas por jesuitas de los siglos XVII y XVIII, pero que no es posible acceder directamente a dichas acciones sino que se presentan mediadas por los escritores de las biografías que analizamos. 


\section{Reflexiones finales}

Los objetivos de la producción historiográfica han cambiado con el correr de los años, sin embargo un historiador escribe desde y para su contexto y con el fin de rescatar de la memoria los sucesos que él considera importantes. En este sentido, no podemos dejar de mencionar que Techo y Orosz escribían desde unas provincias rioplatenses en las que entre 1640 y 1750, pese a que su población había aumentado, y las "ciudades" se consolidan, todavía eran pequeñas aldeas. Pero también escriben para España, para que en todos los noviciados de la Compañía y en las casas de oración se leyera sobre las "proezas" que los jesuitas realizaban para extender la fe católica; así como para fortalecer la posición de la Compañía en el mundo europeo y en el resto de los colegios, ya que muchos padres eran originarios de los colegios del centro-este de Europa.

Como señalamos, este trabajo podía ofrecer tres líneas de análisis; si bien no encontramos respuesta a todas las preguntas que lo orientaron creemos que las razones del trabajo de Techo son claras ya que él era el historiador de la provincia del Paraguay y por lo tanto su trabajo consistía en "rescatar del olvido las buenas obras de los jesuitas". Estos lineamientos sobre la escritura que se inician con las instrucciones de Polanco que normalizan la correspondencia y que posteriormente se definen a partir de la escritura de las biografías de Ignacio por Ribadeneyra y del Cronicon en 1540 relatando la historia de la primera Compañía influeyen en toda la escritura posterior de la Compañía. En este sentido Techo se destacó con su historia y con numerosos trabajos entre los que se cuentan las biografías de padres jesuitas. Sin duda la escritura de este tipo de biografías implicaba la necesidad de reafirmar su espacio desde el presente, que se reitera en los casos de Orosz y Furlong, quienes se proponen recordar por temor a que se olviden dichas "proezas jesuitas". Por eso está presente en la reivindicación del pasado y de las tareas que los jesuitas desempeñaron en el pasado la necesidad de remarcar la utilidad de la Compañía en el presente de cada uno ya que siempre sobrevolaba el temor a perder el recuerdo.

Intentamos centrar nuestra mirada en el caso de Orosz, por considerarlo el más paradigmático - y por esto le dimos mayor tratamiento - ya que él no había sido nombrado historiador como Techo y es contemporáneo a los historiadores Pedro Lozano y José Guevara que figuran con dicho cargo en los catálogos de la Ordenn entre los años 1730 y 1767, aunque no es posible saber cómo eran nombrados o designados y la incumbencia que tenía su cargo. Por esto nos preguntamos sobre el acceso a la escritura, a la publicación y a la circulación de las obras, sobre la posibilidad de que otros jesuitas con diferentes cargos como lo era ser rector del Monserrat - pudieran escribir biografías. Evidentemente la necesidad de la Compañía de mostrarse benefactora para América ofreció dicha licencia a los jesuitas ya que entre 1700 - 1767 hay numerosos escritos de distintos autores que hoy forman un nutrido grupo que espera ser analizado. Por otra parte los objetivos de Orosz 
también eran claros ya que buscaba ofrecer, con fines propagandísticos a los cuales evidentemente la Orden propugnaba, un espacio donde desempeñarse como misionero.

El caso de Furlong es muy diferente ya que escribe en una época en la que la disciplina está establecida como tal, con procesos de análisis determinados, con métodos y técnicas propios que fundamentaban su trabajo, a los cuales él adhiere como integrante del grupo de historiadores que renuevan la historiografía argentina nucleados en la Nueva Escuela Histórica. Por otra parte debemos insistir que permanece en las ideas historiográficas del siglo XIX para las cuales la biografía es una manera de resaltar la vida de grandes hombres como hacedores de la historia, ideas que se mantuvieron hasta bien entrado el siglo XX. Coincidimos que el estudio de Furlong para su Colección de Escritores Coloniales se refiere a los usos que se le dieron a la biografía durante el surgimiento de los Estados Modernos donde las historia nacionales se confundieron con las biografías de los próceres, conjugando sus objetivos con la necesidad de editar fuentes.

Así se encadena por varios siglos la necesidad de dar a conocer los hechos de la vida de los grandes hombres. Las primeras reflexiones que se presentan después de este acercamiento a las biografías de jesuitas por jesuitas se refieren a la necesidad de escribir y lo internalizada que estaba la escritura en los ámbitos jesuíticos. Nicolás del Techo con sus numerosos trabajos comienza una tradición de escritura "oficial" para la provincia del Paraguay aunque siempre en paralelo con la escritura de otros padres. Después de dos siglos de la expulsión, Furlong enmarcado en la historia científica retoma la escritura de las biografías, con el cargo de historiador, por lo que nos preguntamos sobre la necesidad de la Orden de generar y mantener este cargo. Y entre ambos jesuitas, avanzado el siglo XVIII, Ladislao Orosz que, pese a ser contemporáneo de Guevara quien era el historiador de la provincia jesuítica del Paraguay, completa las biografías de algunos padres jesuitas y esto nos lleva a preguntarnos ¿por qué otros padres escribían más allá de los historiadores? ¿Qué los llevaba a escribir superponiendo mutuamente numerosos escritos sobre historias, biografías, pueblos indígenas de la zona? Son preguntas que quedarán abiertas hasta que la documentación y nuestras inferencias nos permitan ir profundizando en el mundo de la escritura entre los jesuitas, que en este caso ofrecen la misma escala de valores en tres siglos diferentes donde resaltar el misionero insigne, hombre santo y prudente, o las hazañas milagrosas que realizan en América, esto llevaba intrínseco remarcar el papel que la Compañía tenía en éstas provincias así como la fábrica de la Historia que construye alrededor de su accionar. 


\section{Referências}

ALCANTARA BOJORGE, Dante. El proyecto historiográfico de Claudio Acquaviva y la construcción de la Historia de la Compañía de Jesús en la Nueva España a principios del siglo XVII. EN: Estudios de Historia Novohispana $\mathrm{N}^{\circ} 40$, enero-junio 2009, Instituto de Investigaciones Históricas-UNAM: México, 2009, pp 57-80.

AYROLO, Valentina. El padre Guillermo Furlong, historiador. In: CONGRESO INTERNACIONAL JESUITAS 400 AÑOS EN CORDOBA, 2000, Córdoba. Actas... Córdoba: Universidad Nacional de Cordoba, 2000. p. 47-58.

BARTHES, Roland. Sade, fourier. Madrid: Loyola, 1997.

CARBONARI, María Rosa. ¿Quién construye la historia? La rehabilitación de los sujetos y la biografía renovada.In: CONGRESO INTEROCEANICO DE ESTUDIOS LATINOAMERICANOS, 2., 2003, Mendoza. Actas.... Mendoza, 2003.

CERTEAU, Michel. La escritura de la historia. Iberoamericana: Mexico, 1993.

CARBIA, R. Historia crítica de la historiografía argentina. Bs As, Coni, 1940.

CARDOZO, Efraín. Historiografía paraguaya. IPGH: México, 1959.

CITRO, S. La representación de los cuerpos indígenas en las obras de Paucke y Dobrizhoffer. En: Proyecto "Lenguas en Peligro, Pueblos en Peligro en Argentina. UBA. Archivo DOBES, 2006.

ESTEVE BARBA, Francisco. Historiografía Indiana. Gredos: Madrid, 1964.

FURLONG, Guillermo. Pedro Lozano y sus observaciones a vargas. Buenos Aires: Librería del Plata, 1959.

FURLONG, Guillermo. Ladislao Orosz y su Nicolas del techo. Bs As: Theoría, 1966.

JAOLINO TORRES, M. M. 2008. O arquivo inaciano na gênese do poder disciplinar: formação, conformação e produção da Companhia de Jesús. In: JORNADAS INTERNACIONALES SOBRE LAS MISIONES JESUITICAS, 12., 2008, Buenos Aires. Actas... Buenos Aires, 2008. p. 1-15.

LEVI, Giovanni. Los usos de la biografía. Annales Esc, n. 6, p. 1325-1336, 1989.

LOZANO, Pedro. Historia de la conquista del Paraguay, Río de la Plata y Tucumán (1745). Estudio preliminar y edición de Ernesto Maeder. Academia Nacional de la Historia: Bs As, 2010. 
LUHMAN, Niklas. La sociedad de la sociedad. Iberoamericana: México, 2006.

MAEDER, Ernesto J.A. Historiografía sobre las misiones jesuíticas de guaraníes. Evaluación del último quinquenio. En: Páginas sobre Hispanoamérica colonial. Sociedad y cultura. Bs. As, PRHISCO - CONICET, 1995

MORALES, Martín María. A mis manos han llegado: cartas de padres generales a la antigua provincia del Paraguay (1608 - 1639). Madrid: Institum Historicum Societatis Iesu, 2005.

MOUTOKÍAS, Zacarías. Gobierno y sociedad en el Tucumán y el Río de la Plata. In: TANDETER, E. La sociedad colonial. Buenos Aires: Nueva Historia Argentina, 2000. p. 355412.

OROSZ, Ladislao. Nicolás del Techo. En: FURLONG, Guillermo. Ladislao Orosz y su Nicolás del Techo. Buenos Aires: Ediciones Theoría, 1966.

PALOMO, F. 2004. De algunas cosas que sucedieron estando en misión: espiritualidad jesuita y escritura misionera en la península Ibérica (siglos XVI - XVII). In: COLÓQUIO INTERNACIONAL, 2004. Actas... Porto, 2004. p. 119-150. Disponível em: <http://ler.letras.up.pt/uploads/ficheiros/3769.pdf>. Acesso em: 22 set. 2008.

PAZ, Carlos. La Nación de los Abipones ¿Un experimento político exitoso? FCH-UNCPBA. Dep. Historia. 2009

PENHOS, Marta, Ver, conocer, dominar. Imágenes de Sudamérica a fines del siglo XVIIl. Siglo XXI Editores, Argentina. 2005.

PINO, F. del y LOÁZARO, C. Lazaro (coords). Visión de los otros y visión de sí mismos. Madrid. Biblioteca de Historia de América 12 CSIC. 1995

QUARLERI, Lia. Los jesuitas en la Rioja colonial. UBA. 2003

REGLAS de la Compañía de Jesús y la carta de la obediencia de nuestro glorioso padre San Ignacio: fórmulas de los votos, y documentos del mismo santo padre. [1735]. Sevilla. Disponible en:<www.cervantesvirtual.com>. Consultado el: 15 jun. 2009.

STORNI, Hugo. Catálogo de los jesuitas de la provincia del Paraguay (Cuenca del Palta) 1585 - 1768. Roma: Institutum HIstoricum Societatis Iesu, 1980.

TELESCA, Ignacio. Tras los expulsos. Cambios demográficos y territoriales en el Paraguay después de la expulsión de los jesutitas. Universidad Torcuato Di Tella. 2009

WILDE, Guillermo. Religión y poder en las misiones de guaranies. UBA. 2003 